\title{
Premières. Les lettres au féminin en 1980
}

Julie Crohas Commans

\section{(2) OpenEdition \\ Journals}

Édition électronique

URL : http://journals.openedition.org/edl/2394

DOI : $10.4000 /$ edl.2394

ISSN : 2296-5084

\section{Éditeur}

Université de Lausanne

\section{Édition imprimée}

Date de publication : 15 mars 2020

Pagination : 131-134

ISBN : 978-2-940331-73-4

ISSN : 0014-2026

\section{Référence électronique}

Julie Crohas Commans, «Premières. Les lettres au féminin en 1980 », Études de lettres [En ligne], 312 | 2020, mis en ligne le 24 mars 2020, consulté le 17 septembre 2020. URL : http://

journals.openedition.org/edl/2394; DOI : https://doi.org/10.4000/edl.2394 


\section{PREMIÈRES. LES LETTRES AU FÉMININ EN 1980}

Le 6 mars 1980, Marguerite Yourcenar est élue à l'Académie française. En obtenant la majorité plus une voix, elle est la première femme en trois cent quarante-cinq ans à y obtenir un fauteuil. La décision reste cependant symbolique, comme en témoigne le propos de Jean Guitton ce jourlà. Aux journalistes qui l'interrogent, il explique avec un sourire qu'il a bien entendu fait partie des opposants: l'Académie ayant vécu pendant trois siècles sans femme, elle pouvait encore vivre trois siècles sans.

La tradition française - rarement pionnière quand il s'agit des droits de la femme - lui donnait alors raison, mais la Compagnie restée trop longtemps exclusivement masculine devait accepter le changement. L'année précédente, Simone Veil - qui sera élue à l'Académie en 2008 - avait été nommée présidente du Parlement européen, et la loi sur l'interruption volontaire de grossesse qui portera son nom, jusqu'alors expérimentale, avait été reconduite sans limite de temps en décembre 1979. Plusieurs tentatives avaient en outre, au cours de la dernière décennie, préparé l'arrivée d'une femme au Quai Conti - en 1971, Françoise Parturier avait reçu une voix; en 1975, Louise Weiss en avait obtenu six et Jeannine Charrat quatre -, et parce que l'Académie royale de Belgique, fondée en 1920 sur le modèle français, avait ouvert ses portes aux femmes, et ce dès sa création - Anna de Noailles fut la première en 1921 ; Colette lui succéda en 1935 et Marguerite Yourcenar en 1970 -, il était grand temps de lever les dernières réticences.

En ce mois de mars 1980, qu'il découle d'un effet de mode, de la pression sociale ou d'une stratégie longuement réfléchie, comme cela fut reproché à Jean d'Ormesson, le résultat de l'élection mit fin à un usage qui, selon les mots de la nouvelle immortelle le jour de son introduction, 
"plaçait [volontiers] la femme sur un piédestal mais ne permettait pas encore de lui avancer officiellement un fauteuil». L'attitude de Marguerite Yourcenar fut, selon certains, ce qui aurait imposé sa candidature, assurant de la sorte une transition apaisée. Les revendications n'en furent pas moins claires: celle qui n'avait pas fait campagne affirma la confiance qu'elle portait en la force et en l'influence féminine. Le 22 janvier 1981, dans son discours de réception, l'écrivaine concéda avec indulgence

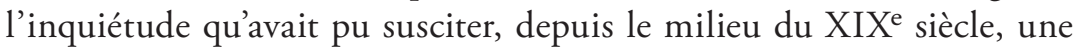
littérature au féminin et se contenta de supposer que «cet état de chose était trop nouveau peut-être pour attirer l'attention d'une Compagnie comme la [leur] ». Elle déclara néanmoins se présenter, face à ceux qui l'accueillirent à l'Institut, "accompagné[e] d'une troupe invisible de femmes", "tentée de s'effacer pour laisser passer leurs ombres». La porte fut entrouverte et elle le resta.

Cette "victoire de la littérature", telle qu'elle fut affirmée par Jean d'Ormesson dans Le Figaro au lendemain de l'élection, précisant que "c'est un écrivain plus qu'une femme qui entr[ait] sous la Coupole» et qui mettait ainsi fin "au mythe de la littérature féminine», ne fut pas aussi définitive qu'annoncée. La question d'une "écriture féminine" telle qu'elle était nommée se posa encore, devrait-on dire toujours, et le "J'avais lu", dont l'académicien aurait voulu qu'il suffise à justifier, ne permit pas de couper court au débat. Peu importe. La tranquille assurance affichée par Marguerite Yourcenar s'impose et fait écho à l'affirmation, en cette année 1980, de nombreuses autres écrivaines. Nathalie Sarraute, qui n'a jamais souhaité commenter la notion d'écriture féminine, affirmant n'être ni homme, ni femme lorsqu'elle écrit, confirme dans L'usage de la parole, les principes établis dans Tropismes. Marguerite Duras, qui se voit offrir par Serge July une chronique dans Libération, pose les conditions de sa collaboration: elle proposera chaque mercredi de juillet à septembre 1980 ce qui sera plus tard publié sous le titre L'été 80. Ce texte, dédié à Yann Andréa Steiner que l'écrivaine vient de rencontrer, marque un moment décisif dans son œuvre. Cette même année, le recueil de nouvelles Femmes d'Alger dans leur appartement annonce également la direction nouvelle prise par Assia Djebar, dans sa vie comme dans son écriture. Il y a là autant de revendications et de convictions distinctement formulées, invitant à ne pas reconnaître les femmes écrivains à titre d'exception. 
Au cours des années suivantes, ce qui s'apparente à une nouvelle ère littéraire s'impose. Des écritures se confirment ou se dévoilent; des tournants s'opèrent; de nouveaux genres naissent et la littérature n'est pas plus féminine que masculine. Simone de Beauvoir publie, en 1981, son dernier texte, La cérémonie des adieux, journal qui retrace dix années de sa vie, s'achevant le 15 avril 1980, date de la mort de Jean-Paul Sartre. En 1983, Nathalie Sarraute et Annie Ernaux bouleversent l'autobiographie avec Enfance et La place. Avec ce dernier texte, Annie Ernaux rend visible le genre nouveau du récit de filiation qui marquera profondément la production littéraire de la fin du siècle. L’année suivante sont publiés L'amant de Marguerite Duras et le premier roman de Sylvie Germain, Le livre des nuits. Un an plus tard, Marie Ndiaye se fait connaître elle aussi avec Quant au riche avenir. Les questions n'en restent pas moins inchangées comme le rappellent en 1983 Anne-Lise Grobéty, Monique Laederach et Amélie Plume dans Écriture féminine ou féministe?, interrogation sur laquelle Christine Planté, l'une des premières à travailler sur la notion de genre en France, reviendra à nouveau à la fin de la décennie avec La petite seur de Balzac sans pour autant clore la discussion, puisque ce texte fut réédité en 2015 et que la thématique est aujourd'hui encore au cœur de nombreuses recherches.

Marguerite Yourcenar est morte en 1987 sans qu'aucune autre femme n'ait siégé à ses côtés. Elles ne furent que neuf jusqu'à ce jour: Jacqueline de Romilly en 1988, suivie d'Hélène d'Encausse, Florence Delay, Assia Djebar, Simone Veil, Danièle Sallenave, Dominique Bona et Barbara Cassin. Il faut du temps pour changer les esprits et surtout, comme l'avait suggéré Marguerite Yourcenar, de la confiance envers les femmes et leur force de conviction, et ce, quelle que soit leur place dans la société ou sur la scène littéraire. Toutes incarnent à leur manière le mot attribué à la première immortelle lors de son installation, l'adjectif «follet", dont la définition rappelle que pour faire entendre une voix nouvelle, il suffit parfois «d'une aimable extravagance».

Julie Crohas Commans

Section de français, Department of Foreign Languages \& Literatures, Auburn University 


\section{BIBLIOGRAPHIE}

Beauvoir, Simone de, La cérémonie des adieux, Paris, Gallimard, 1981. Djebar, Assia, Femmes d'Alger dans leur appartement, Paris, Des Femmes, 1980.

Duras, Marguerite, L'été 80, Paris, Éditions de Minuit, 1980.

—, L’amant, Paris, Éditions de Minuit, 1984.

Ernaux, Annie, La place, Paris, Gallimard, 1983.

Germain, Sylvie, Le livre des nuits, Paris, Gallimard, 1985.

Grobéty, Anne-Lise, Laederach, Monique, Plume, Amélie (éds), Écriture féminine ou féministe?, Genève, Zoé, 1983.

Ndiaye, Marie, Quant au riche avenir, Paris, Éditions de Minuit, 1985.

Planté, Christine, La petite sœur de Balzac. Essai sur la femme auteur, Paris, Seuil, 1989.

Sarraute, Nathalie, Tropismes, Paris, Denoël, 1938.

—, L'usage de la parole, Paris, Gallimard, 1980.

—, Enfance, Paris, Gallimard, 1983.

Yourcenar, Marguerite, Discours, 22 janvier 1981, en ligne sur le site de l'Académie française: <http://www.academie-francaise.fr/ discours-de-reception-de-marguerite-yourcenar>.

Le Journal de 20h, Antenne 2, Archive INA, 6 mars 1980, en ligne: $<$ https://www.ina.fr/video/CAB04007182>. 